\title{
An overview of designing an induction heating system for domestic applications
}

\author{
V. Geetha ${ }^{1}$, V. Sivachidambaranathan ${ }^{2}$ \\ Department of Electrical and Electronics Engineering, Sathyabama Institute of Science and Technology \\ (Deemed to be University), India
}

\begin{tabular}{|c|c|}
\hline Article Info & ABSTRACT \\
\hline Article history: & The inherent benefit of the induction heating system leads to usage in the \\
\hline Received Oct 13, 2018 & manipulated to have highly qualified system. Discussion on the \\
\hline Revised Nov 21, 2018 & customisation of the coil and the converter section is elaborated such that the \\
\hline Accepted Dec 3, 2018 & $\begin{array}{l}\text { design relaying on the load variation, type of coil, rating required for the } \\
\text { specified application. Thus the paper discusses about the design requirement }\end{array}$ \\
\hline Keywords: & $\begin{array}{l}\text { on the domestic induction applications, depicting the criteria to be satisfied } \\
\text { and the results are verified using the AC-AC converter fed induction heating }\end{array}$ \\
\hline $\begin{array}{l}\text { Working coil } \\
\text { Work piece }\end{array}$ & $\begin{array}{l}\text { system with the help of the equivalent circuit of the working coil and the } \\
\text { work piece. }\end{array}$ \\
\hline
\end{tabular}

Copyright $@ 2019$ Institute of Advanced Engineering and Science. All rights reserved.

\section{Corresponding Author:}

V. Geetha,

Research Scholar,

Sathyabama Institute of Science and Technology,

Chennai 119, India.

Email: geethasendray28@gmail.com ${ }^{1}$, sivachidambaram_eee@yahoo.com²

\section{INTRODUCTION}

Induction heating is a process used worldwide for a clean environment. The design procedure of a heating coil plays a major part of the induction heating applications. There are three places where induction heating is applied in domestic areas, medical areas and finally in industries. The classification is according to the wattage required for the specified application for domestic application the maximum wattage required is only 2 kilowatts [1]. The requirement for designing an induction coil for domestic application is analysed and elaborated [2]. The innovated induction heating technology is used in the applications like induction melting, forging, hardening, etc., especially in the field of medicine heating of the biological tissues at a proper temperature for treatment of the tumour and cancer patients during hemotherapy. Basically, the induction heating process requires a copper coil surrounding a metallic work piece. There is a large gap between the coil and the work piece to have a free movement of heat energy. The thermal insulation is provided to the coil so that the radiated heat losses in the coil are reduced [3]. The flux produced by the coil generates the heat energy to the work piece and there will be parallel paths of the flux to flow. With respect to the flow of the flux is according the current flow the total flux depends on the air gap flux, coil flux, work piece flux. Accordingly, the equivalent circuit is derived and the design criteria for the resistance and the inductance and the other parameter are followed in the following section. There are three areas to concentrate on the induction heating; they are power electronic circuit, magnetic components, and modulation and control strategies. The research mostly carried on the power electronic circuit to show the better performance [4]. To improve the heating and to reduce the harmonic content in the produced output modulation and control strategies are concentrated, by this the performance of the system is improved much. The magnetic properties play a major role in the heating concept that is the thickness of the copper coil, type of the coil, shape of the 
coil used decides the amount of energy to be produced and the heating system [5]. The state of art of the review is to provide a knowledge on designing induction heating system for the below mentioned data. Similarly, for the higher values of the temperature and quantity the system can be designed. The solution preferred in the work is that less thickness is the coil higher the heat energy produced and the thicker the coil lesser the energy produced. The other issue to be concentrated is that the selection of the switch and the power circuit developed for the inducting heating system. The next factor to be considered when designing an induction heating system is the power circuit topology, there are different topologies employed for the specified application, utility frequency to be converted to high frequency since it is the high frequency application [6]. Conversion can be carried out with either single stage or multi stage pros and cons of the stage conversion elaborated and single stage conversion leading to better performance of the system [7]. The efficiency of the system depends on the parameters like the size of the pan, heating surface, design of the power circuit topology in addition to the working coil parameters i.e., thickness of the coil, material of the coil and etc].The conversion process can be AC-DC-AC or DC-AC or directly AC - AC etc[8-12].The preferred one will be directly AC-AC conversion, since we have minimum number of switches, complexity of controlling the power circuit will be reduced [13],[14] The following Figures represent few topologies that can be used for domestic induction heating applications. In the multi stage we have different schemes so that control parameter can be varied from part to part.

\section{DESIGN CONSIDERATION OF THE HEATING SYSTEM}

Quantity of water: 1 Litre

Temperature: $100^{\circ}$ Celcius

Material to be used for heating: cast iron

The design procedure for designing a coil totally depends on or similar to the generator winding design. The total outcome of the process dependent on the design of the coil in the induction heating the water to be heated with a iron base.

\subsection{Power required for boiling 1 litre of water to $\mathbf{1 0 0}$ degree celcius}

1 litre of water $=1000$ grams

Approximately weigh of the iron is $400 \mathrm{~g}$

$\Delta \mathrm{T}=85^{\circ} \mathrm{C}(100-15)^{\circ} \mathrm{C}$

Specific heat capacity of water $=4.184 \mathrm{~J} / \mathrm{g}^{\circ} \mathrm{C}$

Specific heat capacity of iron $=0.450 \mathrm{~J} / \mathrm{g}^{\circ} \mathrm{C}$

Power required is assumed to be 1000 watts

Joule $=$ watts $*$ time

Total energy $=$ energy required to heat water + energy required by iron.

Time $=$ amount of heat required $/$ power

$$
\begin{aligned}
& =[[4.184 * 1000 * 85]+[400 * 0.450 * 85]] / 1000 \\
& =370.94 \mathrm{sec} \\
& \approx 371 \mathrm{sec}
\end{aligned}
$$

\subsection{Calculation of current required}

Vrms $/ \sqrt{ } 2=\mathrm{Vpeak} / 2 \pi$

$$
\begin{aligned}
& \mathrm{I}=\mathrm{P} * 2 \pi /(\sqrt{ } 2 * \text { Vpeak }) \\
& =10.32 \mathrm{~A}
\end{aligned}
$$

The switch in the power supply circuit require a current of $10.32 \mathrm{~A}$ and a peak voltage of $215^{*}$ $\sqrt{ } 2=304.0$ Volts.

The electrical equivalent of the induction coil comprises of resistance, inductance, and capacitance for resonating the inductance.

Voltage applied $=304.3 \mathrm{v}$

Current drawn by the switch $=10.32$ amps

Resonant frequency $=23 \mathrm{KHz}$

Switching frequency $=23 \mathrm{KHz}$

The equivalent values for the working coil are evaluated as

Capacitance:

$$
\begin{aligned}
\mathrm{Q}= & \mathrm{CV} \\
& C=\frac{I}{2 \pi F V} \\
\mathrm{C}= & 0.234 \mu \mathrm{F}
\end{aligned}
$$

Inductance:

$$
\mathrm{GO}^{2}=1 / \mathrm{LC}
$$




$$
\begin{aligned}
& \mathrm{L}=1 / \mathrm{G}^{2} \mathrm{C} \\
& \mathrm{L}=\frac{1}{(2 \pi f)^{2} \mathrm{C}} \\
& =20.46 \mathrm{mH}
\end{aligned}
$$

The switching frequency of the circuit is chosen according to the requirement i.e., for the power rating $<2 \mathrm{KW}$, switching frequency to be chosen between $20 \mathrm{Khz}$ to $100 \mathrm{Khz}$, it should also be compared with the resonant circuit or a better performance. With respect to the load the operating frequency is chosen as 23Khz.operating frequency is chosen after calculating the resonating frequency of the equivalent circuit.

It is important to consider the proper design of a coil to fit the need of the load. The design of the coil depends on shape of the coil, thickness of the coil, number of turns, skin effect, proximity effect etc. In the case we have taken pan cake coil is preferred with a flat surface to boil the water to a $100^{\circ} \mathrm{C}$.Generally pancake coil heats from only one side or surface of the in section to the work piece. Proximity effect is nothing, but magnetic field among the adjacent conductors. The coil or the litz wire made of copper which acts as a good conductor to transfer heat energy. Energy efficient pan cake coil as shown in Figure 1.

The principle behind the IH application is electromagnetic induction,

$$
E=N d \emptyset / d t
$$

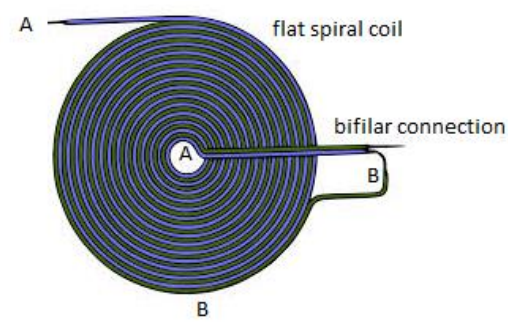

Figure 1. Energy efficient pan cake coil

Preparation of the coil required knowing what the type wire to be used is; solid wire creates more energy loss which reduces the efficiency of the system, so it is better to prefer multistrand litz wire for a energy efficient induction heating system for domestic purpose [15]. The frequency range of a litz wire ranges fron 20 to $50 \mathrm{KHz}$, the size varies between 30 to 36AWG.Sizes are selected depending on the application.

The magnetic field, induced in the coil when energized, creates an eddy current to pass through the work piece and give rise to the heating effect. This eddy current is concentrated on the peripheral of the thickness also called as skin depth.

$$
\text { thickness of the coil }=\frac{5.64 \sqrt{\rho}}{\mu f} \mathrm{~cm}
$$

$\mu=$ permeability of the coil

$\rho=$ electrical resistivity in $\Omega \mathrm{m}$

$\mathrm{f}=$ applied frequency in $\mathrm{Khz}$

The magnetic flux control plays a key role in optimal coil design. The working coil and the work piece arrangement are considered as the transformer arrangement i.e., working coil as primary and work piece as secondary. We need a multi turn cylindrical coil with magnetic flux concentrator. Figure 2 show multi turn cylindrical coil. 


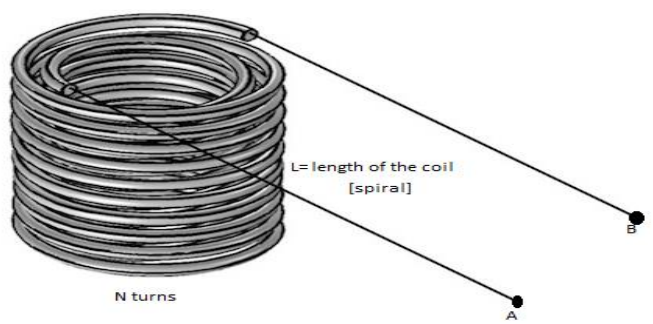

Figure 2. Multi turn cylindrical coil

Local controllers can be used at the end of the coil to control temperature and handling mechanism

The material $=$ copper

Resistivity of the copper $=1.7 * 10^{\wedge}-8 \Omega \mathrm{m}$

Permeability $=1$

Number of strands $=19$ coupled coil.

Number of turns depends on the spacing between the couplings of the coil. Figure 3 show

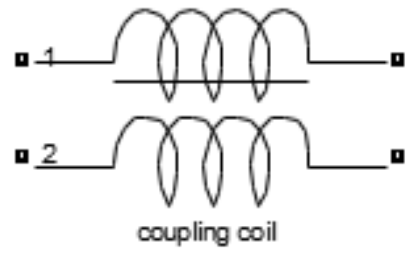

Figure 3. Coupled coil

$N=\operatorname{Rout}-\operatorname{Rin} /(D w p+S)$

Rout $=$ outer radius of the coil

Rin $=$ inner radius of the coil

Dwp $=$ Diameter of the work piece

$\mathrm{S}=$ spacing between the coil turn

Now,

Length of the coil $=\pi N($ Rout + Rin $)$

Length of the twisted coil = length of coil $\sqrt{\left(1+\left(\frac{D b}{P}\right)^{2}\right)}$

$\mathrm{D}_{\mathrm{b}}=$ diameter of the bundled radius

$\mathrm{P}=$ Pitch of the coil

If there is minimum of 10 twists in the coil, inductance is given as Inductance of the coil $=\mathrm{N}^{2} \mathrm{R}^{2} /(8 \mathrm{R}+11 \mathrm{~W})$

$\mathrm{N}=$ total number of turns

$\mathrm{R}=$ radius of the spiral coil

$\mathrm{W}=$ Depth of the coil in inches

To conclude with,

Equivalent inductance of the working coil $=$ inductance of the coil + mutual inductance

Where $\mathrm{M}=\mathrm{R} / 2$ pi $\mathrm{F}$

Resistance of the coil:

Resistance of the coil depends on the length, cross sectional area and resistivity of the coil

$R=\rho l / A$

$\rho(T)=\rho(T o)+(1-\alpha(T-T o))$ 
$\alpha=$ temperature co efficient.

$\rho(T)=$ resistivity of given temperature.

$\rho(\mathrm{To})=$ resistivity of a ambient temperature.

When the temperature varies resistance of the coil varies.

$\mathrm{R}_{\mathrm{T}}=\mathrm{R}_{0} \mathrm{t}_{\mathrm{f}}$

$\mathrm{T}_{\mathrm{f}}=$ temperature factor

$\mathrm{R}_{0}=$ resistance of ambient temperature

$\mathrm{R}_{\mathrm{COIL}}=\mathrm{R}^{*} \mathrm{r}_{\mathrm{COIL}} / 2 \delta_{\mathrm{COIL}}$

$\mathrm{R}_{\mathrm{coil}}=$ radius of the working coil

$\delta_{\mathrm{COIL}}=$ penetration depth of the working coil

To have a proper and efficient boiling point of a material the heat transfer should have high conduction, moderate convection and less radiation. Higher the heat transfer lowers the cooking time. Temperature is the property of the material independent of how much the quantity is. Heat or thermal energy is a measure of amount of energy in a material.

\section{Thermal properties of water:}

1. Heat capacity $=4.2 \mathrm{~J} / \mathrm{Kg}$

2. Thermal conductivity $=0.02 \mathrm{~J} / \mathrm{Sec}$

3. Effective temperature range $=32-212^{\circ} \mathrm{F} / 0-100^{\circ} \mathrm{C}$

Impedance matching circuit:

The induction heating application has to be driven with a maximum power so transfer of power from the coil to the work piece so the equivalent impedance of the circuit has to be determined only then the appropriate impedance matching circuit can be chosen to yield a conjugate matching to the operating frequency. Always the source impedance is much higher than the load impedance. The primary as working coil and secondary as work piece, now this model is modeled in terms of an equivalent circuit. Figure 4 show matching circuit.

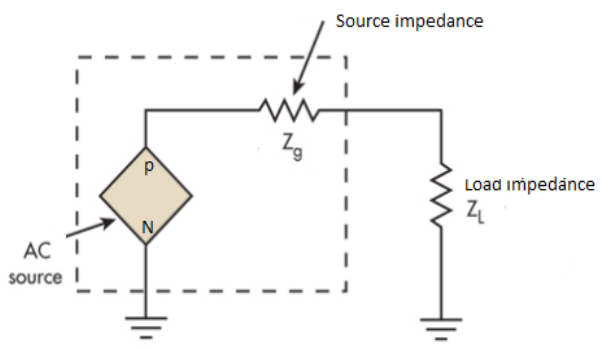

Figure 4. Matching circuit

We know that,

$$
\mathrm{I}_{\mathrm{S}} \mathrm{N}_{\mathrm{S}}=\mathrm{I}_{\mathrm{P}} \mathrm{N}_{\mathrm{P}}
$$

If the number of turns in the secondary is considered as 1

$$
\mathrm{I}_{\mathrm{S}}=\mathrm{I}_{\mathrm{P}} \mathrm{N}_{\mathrm{P}}
$$

Power required for the work piece is $I^{2} R$ watts

$\mathrm{P}=(\mathrm{IpNp}) 2 \mathrm{R}$

$\mathrm{P}=\left((\mathrm{IpNp})^{2} \rho \pi \mathrm{D}\right) / 81$

$$
\begin{aligned}
& \delta=\text { skin depth } \\
& \mathrm{l}=\text { length of the work piece }
\end{aligned}
$$

\section{Density of the power:}

$$
\mathrm{PDEN}=\mathrm{P} / \pi \mathrm{D} l
$$

$\pi \mathrm{D} l=$ area of the cylinder

$\mathrm{P}=$ Power produced in the coil (watts)

An overview of designing an induction heating system for domestic applications (V. Geetha) 
Density of the power is calculated to know the distribution of the heat energy or the flux in the work piece so that the effect of heat distributed influencing the medium can be clarified.

\section{CONCLUSION}

Thus, the paper depicts the analysis and design of the induction coil for the domestic applications and the power circuit of the single stage half bridge system is shown for the qualitative analysis of the system. The tremendous improvement in the system is seen and the results for the designed coil is imposed in the simulation and shown in the above Figures. Thus, to conclude the power circuit configuration selection also plays an important role in analysis of the designed system.

\section{REFERENCES}

[1] Pradip Kumar Sadhu, Palash Pal, Nitai Pa and Sourish Sanyal, "Selection of Power Semiconductor Switches in M.H.B.R.I. Fitted Induction Heater for Less Harmonic Injection in Power Line”, International Journal of Power Electronics and Drive System (IJPEDS), ISSN: 2088-8694, Vol. 6, No. 1, pp. 121 128, March 2015.

[2] H. Sarnago, O. Lucia, A. Mediano, and J.M. Burdio, "Class-D/DE dual-mode-operation resonant converter for improved-efficiency domestic induction heating system”, IEEE Trans. Power Electron., vol. 28, no. 3, pp. 1274- 1285, Mar. 2013

[3] Kunapuli sahiti and V.Geetha," Simulation of series resonant inverter using pulse density modulation" $A R P N$ journal of engineering and applied sciences, ISSN 1819-6608, Vol.10, No.7,pp.3045-3051, April 2015.

[4] O. Lucía, C. Carretero, J. M. Burdío, J. Acero, and F. Almazán,"Multiple-output resonant matrix converter for multiple induction heaters," IEEE Trans. Ind. Appl., vol. 48, no. 4, pp. 1387-1396, Jul./Aug. 2012

[5] V. Sivachidambaranathan, "High frequency isolated series parallel resonant converter," Indian Journal of Science and technology, ISSN (Print) : 0974-6846 ISSN (Online) : 0974-5645, Vol 8(15), 2015.

[6] K Selvamuthukumar, M Satheeswaran, A Ramesh Babu, "Single phase thirteen level inverter with reduced number of switches using different modulation techniques", ARPN Journal of Engineering and Applied Sciences, Vol. 10, No. 22, pp.10455 - 10462, 2015.

[7] Chudjuarjeen, S. and Koompai, C., “A High-Frequency Induction Cooker using Qusai-resonant Converter”, ECTIConf. 2007 pp.378-381/2007.

[8] V.Geetha, V.Sivachidambaranathan, "A Single switch parallel quasi resonant converter topology for induction heating application", International Journal of Power Electronics and Drive System (IJPEDS), ISSN: 20888694, Vol.9,no.4,December 2018, pp. 1718 1724.

[9] H. Sarnago, O. Lucía, A. Mediano, and J. M. Burdío, "High efficiency parallel quasi-resonant current source inverter featuring $\mathrm{SiC}$ MOSFETs for induction heating systems with coupled inductors," IET Power Electron., vol. 6, no. 1, pp. 183-191, Jan. 2013.

[10] H. W. Koertzen, J. A. Ferreira, and J. D. van Wyk, "A comparative study of single switch induction heating converters using novel component ef- fectivity concepts," in IEEE PESC, pp. 298-305, 1992.

[11] V. Sivachidambaranathan. 2014. "Bi-Directional Series Parallel Resonant Converter For Power Factor Correction," International Journal of Applied Engineering Research. ISSN 0973-4562, Vol.9, No.21.2014.

[12] A.Ramesh Babu, "Comparative analysis of cascaded multilevel inverter for phase disposition and phase shift carrier PWM for different load", Indian Journal of Science and Technology, Vol 8(S7), ISSN (Print) : 0974-6846 ISSN (Online) : 0974-5645,pp. 251 - 262, 2015.

[13] Bishwajit Saha and Rae-Young Kim, "High Power Density Series Resonant Inverter Using an Auxiliary Switched Capacitor Cell for Induction Heating Applications", IEEE Transactions on Power Electronics, vol. 29 (4), pp. 1-3, April 2014.

[14] H. Sarnago, O. Lucia, A. Mediano, and J.M. Burdı, "Direct ac-ac resonant boost converter for efficient domestic induction heating applications", IEEE Trans. Power Electron., no. 2014.

[15] M.saravanan,A.Ramesh Babu,"High Power Density Multi MOSFETt based series resonant inverter for Induction Heating Applications" International Journal Of Power Electronics and Drive System (IJPEDS), ISSN 2088-8694 Volume 7 no.1pp 107-113, 2016. 